\title{
A VENTILATOR ADAPTER FOR FIBREOPTIC BRONCHOSCOPY
}

\author{
R.E. NEEDS, M.B., B.CH., F.R.C.P.(C)
}

THE INTRODUCTION of the flexible fibreoptic bronchoscope by Ikeda ${ }^{1-2}$ has been a major advance in instrumentation for diagnostic bronchoscopy. Its use has also been described in segmental and subsegmental bronchial catheterization for radiological investigation ${ }^{3}$ and in the management of respiratory failure. ${ }^{4}$ Techniques used most commonly employ topical analgesia and the passage of the instrument through an endotracheal tube or rigid bronchoscope as described by Ikeda. The nose ${ }^{5}$ and a nasopharyngeal tube $e^{6}$ have also been advocated as routes of introduction. In his report on general anaesthesia for bronchofibreoscopy Tahir ${ }^{7}$ described a technique almost identical to the one developed independently by the author.

The method used at the Sunnybrook Medical Centre involves a general anaesthetic/relaxant technique with intermittent positive pressure ventilation utilizing a specially designed adapter to facilitate the passage of the fibreoptic bronchoscope whilst maintaining ventilation. This method is preferred by the thoracic surgeons of the hospital and the advantages of the technique from the endoscopist's viewpoint have been outlined previously. ${ }^{8}$ No complications related to the method have been observed in 256 cases bronchoscoped between February 1971 and April 1974. Blood gas measurements during the early part of the series confirmed the adequacy of ventilation. The purpose of this report is to describe the Sunnybrook fibreoptic adapter which is felt to have certain advantages over equipment previously described.

\section{Apparatus}

The adapter (Figures 1 and 2) is a semi-transparent high-impact plastic elbow with 15-mm male and female fittings. The bronchoscope port is sealed with a detachable latex bottle cap perforated in the centre by a $4.5-\mathrm{mm}$ hole which can be closed by an attached bung to prevent leaks when the bronchoscope is not in place. The recessed $15-\mathrm{mm}$ female end provides a smooth internal surface between the adapter and the straight endotracheal connector (Figure 3). This allows unimpeded passage of the bronchoscope through the endotracheal tube. The anaesthetic machine or ventilator is connected to the $15-\mathrm{mm}$ male side arm in the usual fashion (Figure 4). The unit has an internal volume of $6 \mathrm{ml}$ and weighs only $25 \mathrm{gm}$.

Using a 9-mm cuffed tracheal tube and with the Olympus BF type 5B bronchoscope in situ, the expiratory resistance is approximately $3 \mathrm{~cm}$ water. This rises markedly with a smaller tube and tubes of internal diameter less than $8 \mathrm{~mm}$ are 


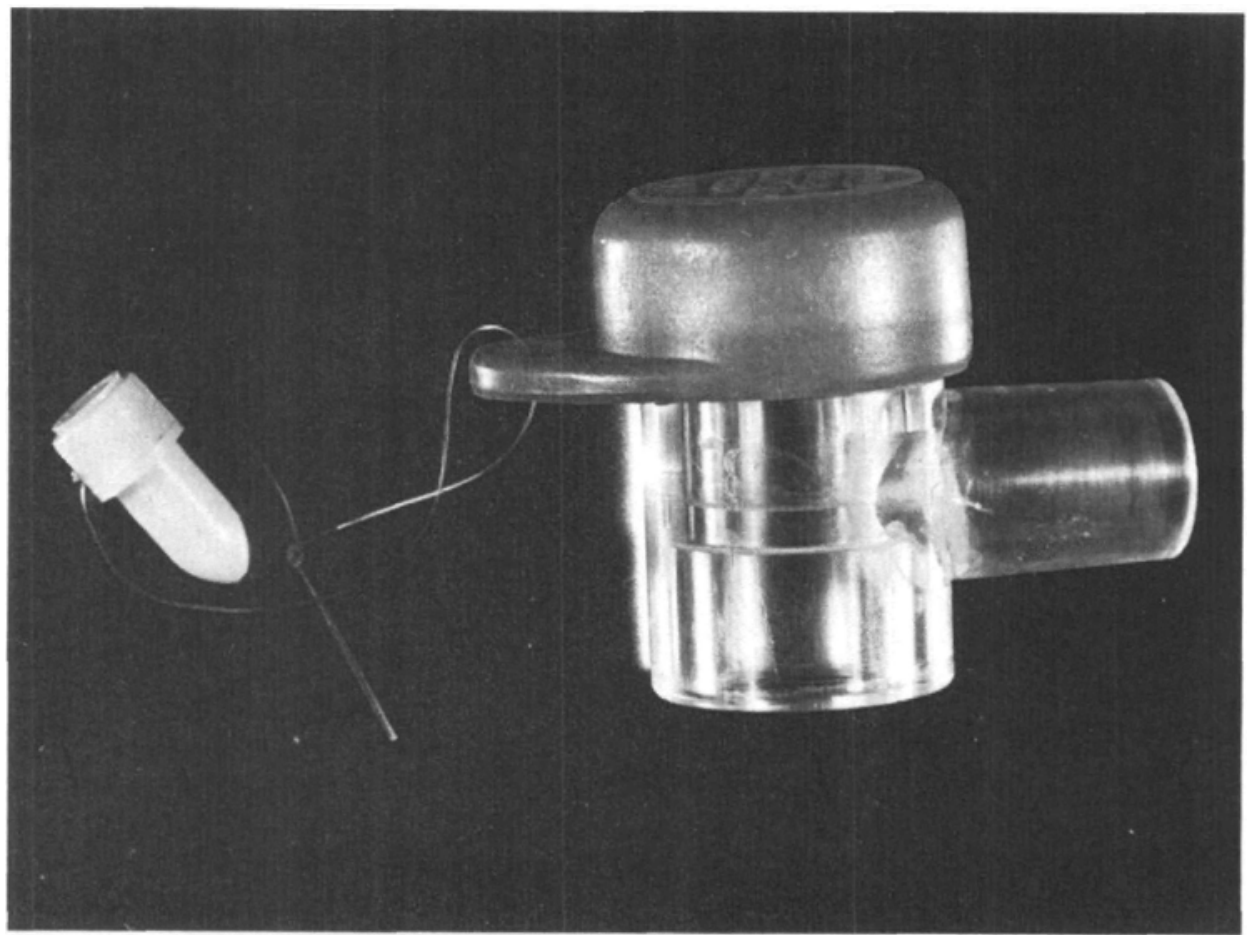

Figure 1. A ventilator adapter for fibreoptic bronchoscopy.

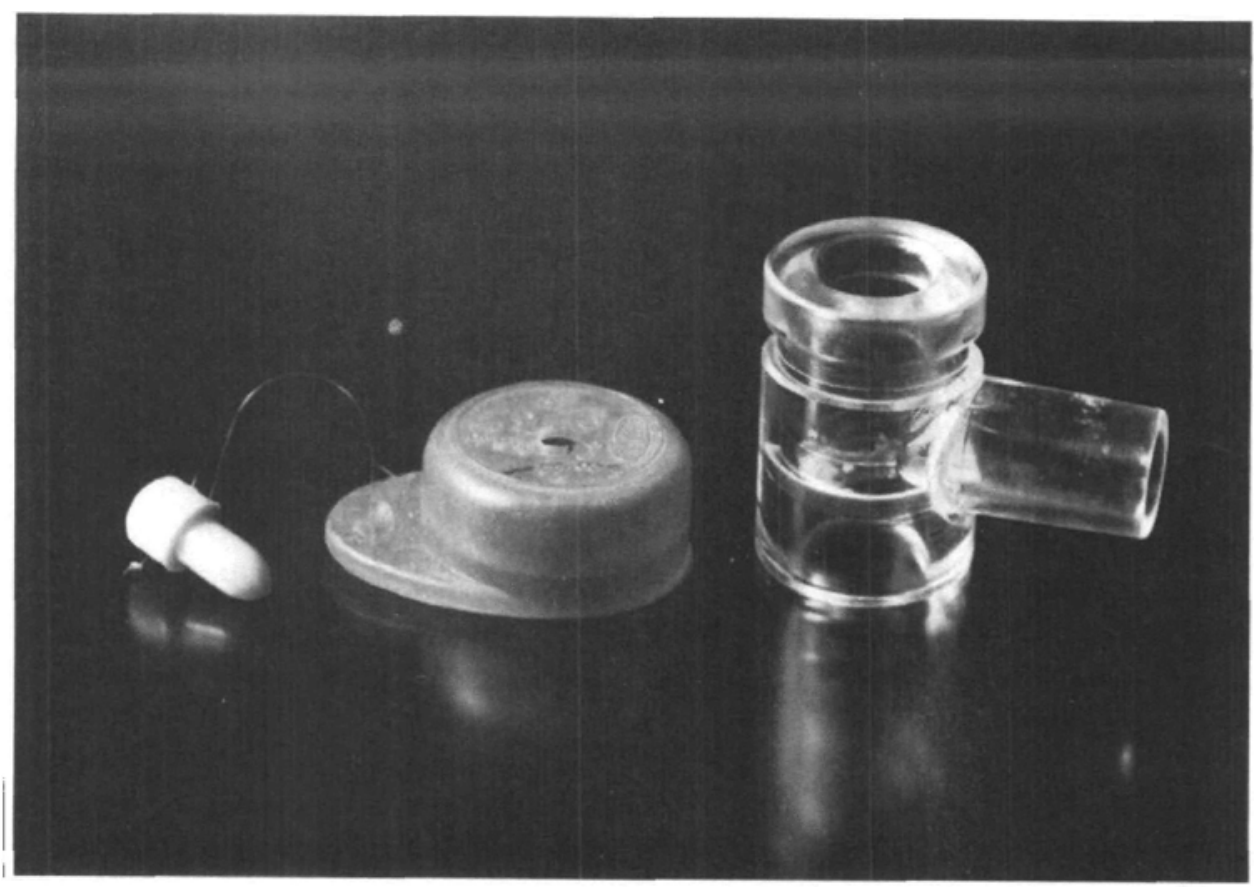

FIGURe 2. A ventilator adapter for fibreoptic bronchoscopy. 


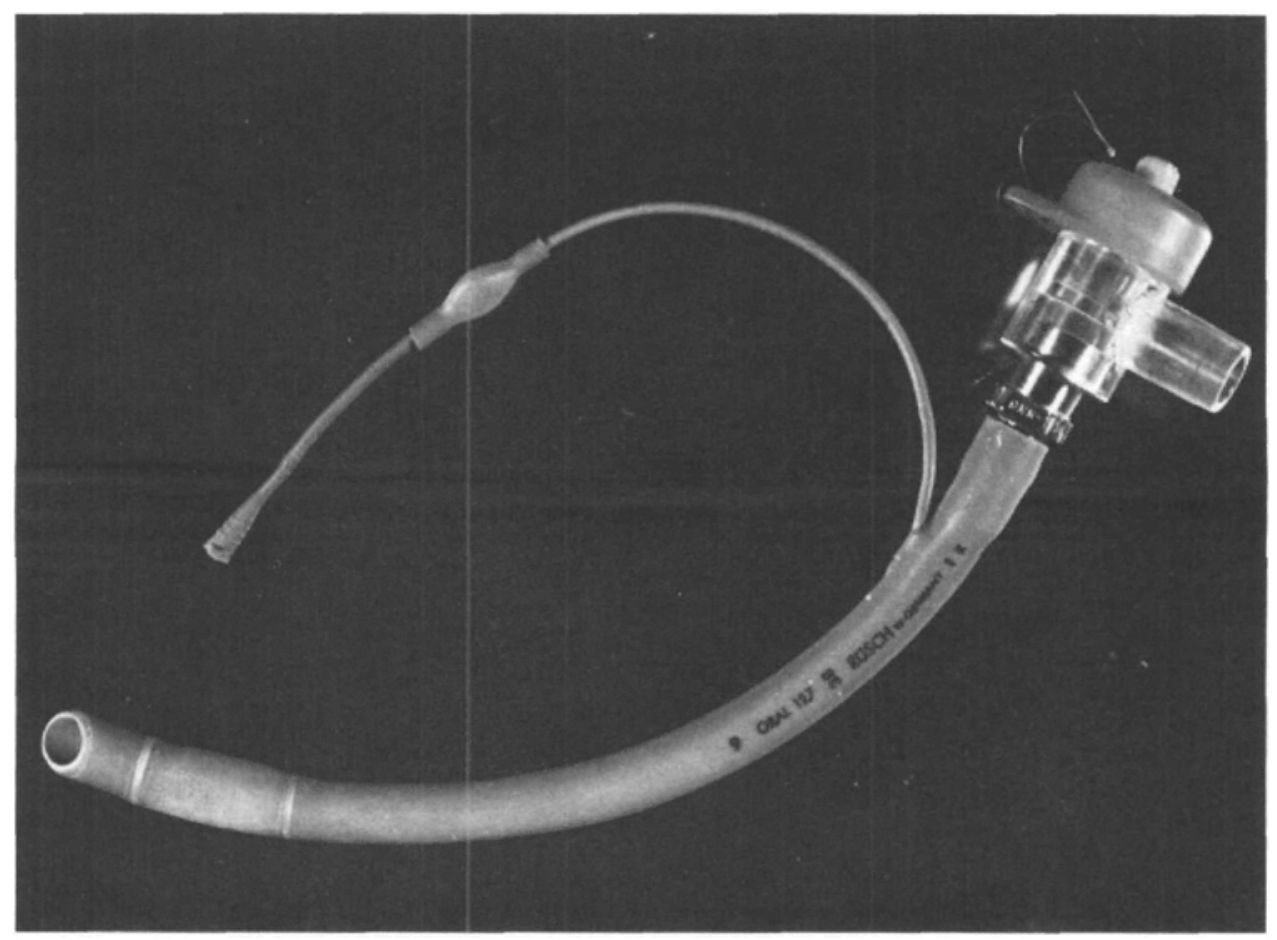

Figune 3. A ventilator adapter for fibreoptic bronchoscopy.

impractical for this reason. The use of the newer smaller bore bronchoscopes should allow a correspondingly smaller tube to be used.

We have also found the adapter invaluable in the diagnostic and therapeutic management of patients in respiratory failure maintained on ventilators. Bronchoscopy and bronchial suction under direct vision can be achieved without jeopardizing the ventilation, merely by interposing the adapter between the ventilator and the tracheal or tracheostomy tube.

The unit is simple, rugged, withstands various methods of sterilization and when the latex cap requires replacement (which is infrequent) it can be done cheaply and easily.

\section{SUMMARY}

An adapter (Sunnybrook Fibreoptic Adapter) is described which permits the use of intermittent positive pressure ventilation during bronchoscopy with the flexible fibreoptic bronchoscope, under general anaesthesia or in patients in respiratory failure maintained on ventilators.

\section{ACKNOWLEDGMENTS}

I wish to express my thanks to Mr. Frank Benham, Inhalation Therapy Technician, Sunnybrook Medical Centre for invaluable assistance in producing the prototype. 


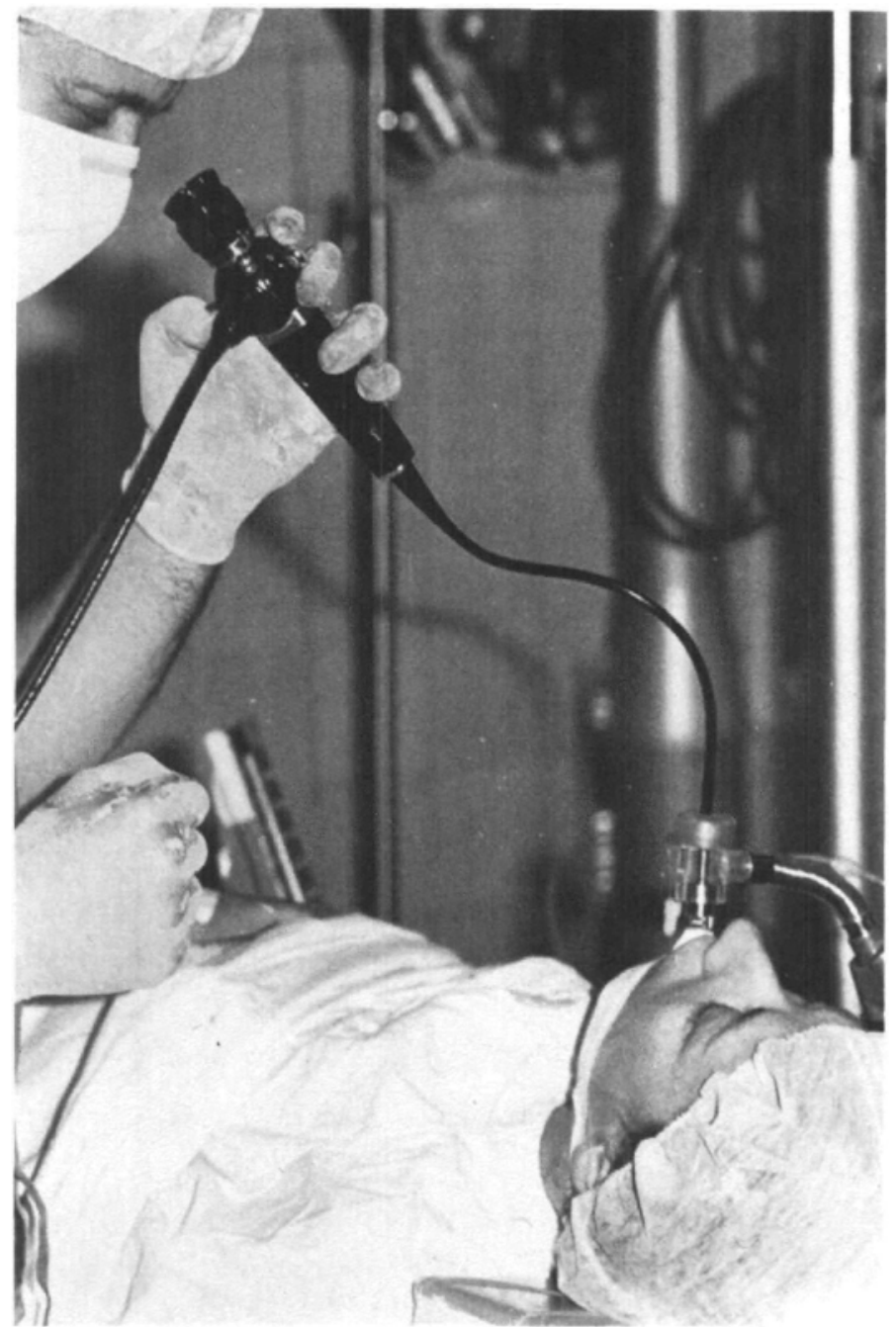

Figure 4. A ventilator adapter for fibreoptic bronchoscopy.

The adapter can be obtained from Industrial Medical Products Ltd., P.O. Box 145, Newmarket, Ontario. (117 Joseph Street)

\section{RÉSUMÉ}

Nous avons décrit un raccord (Sunnybrook Fibreoptic Adapter) qui permet l'emploi de ventilation par pression positive intermittente appliquée sur un bronchoscope flexible de type "Fibreoptic" soit au cours de l'anesthésie générale, soit chez les patients en insuffisance respiratoire nécessitant un ventilateur.

\section{REFERENCES}

1. IKEDA, S. Flexible bronchofibrescope. Keio J. Med. 17: 1 (1968).

2. IKEDA, S. Flexible bronchofibrescope. Annals of Otol-Rhinol. Laryngel 79: 916 (1970). 
3. Fennessy, J.D. Selective catheterization of segmental bronchi with the aid of the Hexible fibreoptic bronchoscope. Radiology 95: 689 (1970).

4. Renz, L.E., Smiddy, J.W., Rauscher, C.R., et al. Bronchoscopy in respiratory failure (Letter to Editor). J.A.M.A. 219:619 (1972)

5. SMmDy, J.W., Ruth, W.E., KerBy, G.R., et al. Flexible fibreoptic bronchoscope. Annals of Int, Med. 75: 971 (1971).

6. Wanner, A., Zighelborm, A., \& Sachner, M.D. Nasopharngeal airway: a facilitated access to the trachea. Ann. Int. Med. 75: 593 (1971).

7. TAHIR, A.H. General anaesthesia for bronchofluoroscopy. Anesthesiology 37: 564 (1972).

8. KeITH, R.G. \& TAYLOR, G.A. Use of the flexible fibreoptic bronchoscope in the diagnosis of malignant tumors of the lung. Cdn. Jr. of Surg. 16:118 (1973). 